\title{
Evaluating free school fruit: results from a natural experiment in Norway with representative data
}

\author{
Arnstein $\varnothing_{\text {vrum }}{ }^{1, *}$ and Elling Bere ${ }^{2}$ \\ ${ }^{1}$ Norwegian Agricultural Economics Research Institute, PO Box 8024 Dep, N-0030 Oslo, Norway: \\ ${ }^{2}$ Department of Public Health, Sport and Nutrition, University of Agder, Kristiansand, Norway
}

Submitted 24 January 2013: Final revision received 27 June 2013: Accepted 13 August 2013: First published online 20 September 2013

\begin{abstract}
Objective: To assess impacts of the nationwide Norwegian School Fruit Scheme

(NSFS) using nationally representative data.

Design: The NSFS is organized such that primary-school children (grades 1-7) are randomly assigned to one of three school fruit arrangements: (i) the child receives one free fruit or vegetable per day; (ii) the child is given the option to subscribe to one fruit or vegetable per day at a subsidized price; and (iii) the child attends a school that has no school fruit arrangement.

Setting: Data from an Internet survey are used to compare child and parental fruit and vegetable intakes across the three NSFS groups focusing mainly on groups (i) and (iii). The analysis was conducted using multivariate regression techniques. Subjects: Parents of primary-school children ( $n$ 1423) who report on behalf of themselves and their children.

Results: Children who receive free school fruit eat on average 0.36 more fruit portions daily - or $25.0 \%$ more fruits - than children who attend schools with no fruit arrangement $(P<0 \cdot 001)$. Moreover, parents of children who receive free school fruit eat on average $0 \cdot 19$ more fruit portions daily - or $12.5 \%$ more fruits than parents of children who attend schools with no fruit arrangement $(P=0 \cdot 040)$. No significant associations were found between the NSFS and the vegetable intakes of children and their parents.

Conclusions: The study shows, using nationally representative data, that free school fruit is associated with increased child fruit intake and that it may also affect parental fruit intake.
\end{abstract}

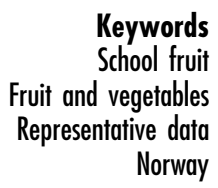

Keywords

School fruit

Representative data

Norway
Dietary habits formed during childhood and adolescence may be difficult to alter at later ages ${ }^{(1,2)}$. Nutrition education programmes in schools represent a potentially important policy tool in impacting such habit formation $^{(3,4)}$. Such programmes often involve encouraging the consumption of more fruit and vegetables $(\mathrm{F} \& \mathrm{~V})$. There are several reasons for this. First, an adequate intake of $\mathrm{F} \& \mathrm{~V}$ has been shown to protect against a number of adverse health outcomes ${ }^{(5)}$. Second, in many countries including Norway, few children and adults meet recommendations by the WHO of eating at least $400 \mathrm{~g}$ of F\&V daily ${ }^{(6,7)}$. Finally, in terms of school logistics, in particular fruits, and partly also vegetables, are easy to distribute and require little preparation time.

School programmes for increased F\&V consumption may include one or several components, including, for example, specific $\mathrm{F} \& \mathrm{~V}$ projects in food and health subjects, parental involvement, school cafeteria interventions and actual provision of $F \& V$ to the pupils, either free or at a subsidized price ${ }^{(3,8-16)}$. Experiences from this last type of intervention - actual provision of $F \& V$ to the pupils - have generally been positive, although the evidence on whether it leads to sustained increases in $\mathrm{F} \& \mathrm{~V}$ intake $2-3$ years after the intervention period is both scarce and mixed ${ }^{(3,8-11)}$.

Most impact assessments of school fruit interventions that involve $F \& V$ provision have been based on relatively small-scale randomized or non-randomized controlled trials in the USA, New Zealand and various European countries $^{(3)}$. These include pilot studies intending to map the potential effects of nationwide school fruit schemes ${ }^{(8,9,13)}$. In the USA, elementary schools with a high proportion of low-income students are eligible for receiving free school fruit through the Fresh Fruit and Vegetable Program. However, due to its design, it is generally difficult to assess the impact of this scheme on the children's F\&V intake ${ }^{(17)}$. The European Union (EU) launched a school fruit scheme in the school year $2009 / 10^{(18)}$. However, due to its recent implementation and a somewhat slow start-up phase ${ }^{(19)}$, it will probably take some time before thorough impact assessments of the EU school fruit scheme may be conducted. 
Nationwide school fruit schemes have now existed for some years in Norway and the UK. However, these schemes have thus far only been assessed using data from certain counties or regions within these countries ${ }^{(10-12)}$. Since the school year 2007/08, the Norwegian School Fruit Scheme (NSFS) has been organized such that primary-school children (grades 1-7) are randomly assigned to one of three school fruit arrangements: (i) the child receives one free fruit or vegetable per day; (ii) the child is given the option to subscribe to one fruit or vegetable per day at a subsidized price, with the daily cost of Norwegian kroner (NOK) 3.50 (approximately €0.50) being shared between the government (NOK $1 \cdot 00)$ and the parents (NOK 2.50); and (iii) the child attends a school that has no school fruit arrangement. Based on surveys from September 2001 and 2008 of 6th and 7th grade children from twenty-seven schools in two Norwegian counties, Bere et $a l{ }^{(12)}$ found that free school fruit and subsidized school fruit increase a child's fruit intake by 0.58 and 0.23 portions/d, respectively.

The objective of the present study is to assess impacts of the NSFS. There are three novel features of this study. First, unlike previous assessments of school fruit interventions, including the NSFS, our study is based on data from a nationally representative sample of primary-school children and their parents; all nineteen counties of Norway and more than 750 different schools are represented in our sample. Second, our study includes children from all grades of primary school. And third, our study also includes data on parental F\&V intake, which allows for assessing the associations between NSFS participation and F\&V intake among both primary-school children and their parents.

\section{Methods}

\section{The Norwegian School Fruit Scheme}

The NSFS started as a test project in the mid-1990s. It grew gradually in scope and was made nationwide in the school year 2003/04. It was then arranged as a subscription scheme in primary schools (grades 1-7), lower secondary schools (grades 8-10) and combined primary and lower secondary schools (grades 1-10). In this version of the NSFS, which still runs in primary schools (grades 1-7), the school first decides whether it wants to participate in a subsidized fruit subscription scheme. Currently, about $57 \%$ of eligible primary schools participate in this subscription scheme. In the participating schools, subscription to one daily fruit (or occasionally vegetable) is optional for each child at a current cost of Norwegian kroner (NOK) $2 \cdot 50 / \mathrm{d}$. This is matched by a subsidy from the Norwegian Ministry of Health and Care Services of NOK $1 \cdot 00 / \mathrm{d}$. Currently, about $30 \%$ of the children in participating primary schools subscribe to subsidized school fruit ${ }^{(20)}$.
In the school year 2007/08, the NSFS was changed from a subsidized subscription scheme (with parental payment) to a free fruit scheme (with no parental payment) in lower secondary schools (grades 8-10) and combined schools (grades 1-10) ${ }^{(21)}$. Thus, since the school year 2007/08, children in school grades 1-7 fall within one of the following four NSFS groups: (i) the child attends a primary school (grades 1-7) that participates in the NSFS and subscribes to subsidized fruit (labelled SUBFRYES); (ii) the child attends a primary school that participates in the NSFS and chooses not to subscribe to subsidized fruit (SUBFRNO); (iii) the child attends a primary school that chooses not to participate in the NSFS and is thus not given the option to subscribe to subsidized fruit (NOFRUIT); and (iv) the child attends a combined school (grades 1-10) and thus receives free fruit as a result of the changes made to the NSFS in the school year 2007/08 (FREEFRUIT). Currently, about $45 \%$ of all primary-school children in Norway attend combined schools and thus receive a free fruit daily in school. Whether a child belongs to NSFS group (i or ii), (iii) or (iv) is largely the result of a random process. The NSFS thus constitutes a natural experiment, since treatment assignment is random and the result of national school fruit policies, rather than being controlled in the traditional sense of a randomized trial.

The NSFS is financed by several Norwegian Ministries, while the Norwegian Fruit and Vegetable Marketing Board is the main administrator of the scheme. In 2011, the total costs for the free and subsidized versions of the NSFS were NOK 230 million and NOK 18 million, respectively.

\section{Data source}

The data of the present study are drawn from an Internet survey in which the respondents are parents of primaryschool children in Norway ( $n$ 1536). The survey was carried out in March 2011 by a professional survey company (TNS Gallup) on behalf of the Norwegian Fruit and Vegetable Marketing Board. The respondents were recruited from TNS Gallup's Internet panel, which consists of approximately 60000 Norwegian adults who, based on telephone recruitment, have agreed to participate in Internet surveys on various themes. The target group in the present study is adults between 25 and 60 years of age with children who attend primary school. To target a nationally representative sample within this age range, a stratified random sample was extracted from the Internet panel based on age, gender, education and geographic region. Within the stratified random sample, all parents of primary-school children received survey invitations by email with a hyperlink to the Internet survey itself. Not all parents responded to this invitation, and to correct for sample selection in the final sample, the later analyses therefore use survey weights.

The initial survey questions were used for screening purposes, asking the parents indirectly to which NSFS 
group their child belonged. Quotas were then used to obtain a sufficient number of respondents across the four NSFS groups: SUBFRYES ( $n$ 342), SUBFRNO ( $n$ 512), FREEFRUIT ( $n$ 274) and NOFRUIT ( $n$ 295). Although a total of 1536 parents were initially surveyed, our final sample consists of 1423 respondents; twenty-nine respondents were excluded due to unknown or uncertain NSFS group; twenty-six respondents had a child who participated in an alternative, school-specific fruit arrangement (outside the NSFS system); and a further sixty-two respondents were excluded due to incomplete data on either child or parental F\&V intake. Respondents from all nineteen counties of Norway and more than 750 different schools are represented in the final sample. The number of respondents per school ranges from one to seven.

Ethical approval was not required for this research; we represent a third party user of the data in question and we only have access to a data file that contains anonymous data, i.e. we do not have access to any information that can be used to identify specific individuals.

\section{Groups analysed}

In the following, respondents from fruit subscription schools (SUBFRYES and SUBFRNO) are subsumed into one group labelled SUBFRUIT ( $n$ 854). There are two reasons for this. First, in the present study we are mainly interested in comparing $\mathrm{F} \& \mathrm{~V}$ intakes across the FREEFRUIT and NOFRUIT groups, because these two groups have typically constituted the intervention group and the control group in previous school fruit intervention studies $^{(3)}$. Second, while attending a SUBFRUIT school is the result of a random process, the choice between SUBFRYES and SUBFRNO, conditional on attending a SUBFRUIT school, may depend on observable and unobservable household characteristics that are also related to baseline $\mathrm{F} \& \mathrm{~V}$ consumption in absence of the NSFS. Thus, in our analysis, we compare F\&V intakes across the three NSFS groups FREEFRUIT, SUBFRUIT and NOFRUIT.

\section{Outcome variables}

The parents were asked to indicate both their own intake and the child's intake of (i) fruits (excluding fruit juices) and (ii) vegetables (fresh, canned and frozen, excluding potatoes) on a typical day. The survey text included examples of portion sizes (e.g. an apple, a bunch of grapes, a handful of vegetables) and the respondents were asked to indicate daily intake on the following scale: 'less than 1 portion' ( $0 \cdot 0)$; ' 1 portion' ( $1 \cdot 0)$; 'between 1 and 2 portions' ( $1 \cdot 5)$; '2 portions' $(2 \cdot 0)$; 'between 2 and 3 portions' $(2 \cdot 5)$; ' 3 portions' $(3 \cdot 0)$; 'more than 3 portions' (3.5); and 'don't know/remember' (missing). We have created six outcome variables based on these ordinal-scaled questions: child/parental fruit intake (FRC/FRP), vegetable intake (VEC/VEP) and total F\&V intake (FRVEC/FRVEP).
To operationalize the later analyses, these variables were made semi-continuous by assuming daily intakes corresponding to the numbers listed in parentheses after each response category above. For robustness purposes, all statistical analyses of the present study have been reiterated using F\&V variables with the original, ordinal coding (using ordered probit models). No significant differences between the semi-continuous and the ordinalcoded F\&V variables were detected in terms of our main results and conclusions.

\section{Explanatory variables}

The key explanatory variables in the analyses of the present study, the NSFS groups FREEFRUIT, SUBFRUIT and NOFRUIT, are described above. To account for possible sampling differences across these groups, in the later regression analyses we also control for relevant child (school grade, gender), parental (age, gender, marital status, education) and household (income, geographic region) characteristics. The parental characteristics are recorded only for the parent who responded to the survey. The different explanatory variables are described in more detail in Table 1.

\section{Statistical analysis}

Associations between NSFS participation and child/parental fruit intake (FRC/FRP), vegetable intake (VEC/VEP) and total F\&V intake (FRVEC/FRVEP) are analysed using multivariate linear regression models (ordinary least squares). The NSFS is organized such that the effects of SUBFRUIT and FREEFRUIT on F\&V intake are assumed to be identified conditional on controlling for child, parental and household characteristics. This is sometimes referred to as the unconfoundedness assumption; treatment assignment is believed to be randomized conditional on relevant pretreatment control variables ${ }^{(22)}$. The multivariate regression models for our six F\&V indicators thus control for SUBFRUIT and FREEFRUIT, as well as child, parental and household characteristics. Children with no fruit arrangement in school and their parents (NOFRUIT) represent the reference group in our models. Although potentially suffering from self-selection issues, we also briefly discuss results from models in which the SUBFRUIT group has been split into subscribing and non-subscribing children, i.e. SUBFRYES and SUBFRNO. As noted, because the choice between SUBFRYES and SUBFRNO, conditional on attending a SUBFRUIT school, may depend on unobservable household characteristics that are also related to baseline F\&V consumption in absence of the NSFS, the results from this alternative model specification must be interpreted with caution.

All of the statistical models in the study are estimated using survey weights and robust standard errors. Data were analysed using the statistical software package Stata 12 and a significance level of 0.05 was used in all statistical analyses. 


\section{Results}

\section{Descriptive statistics}

Table 1 displays variable descriptions and mean values, both for the total sample and split by the three NSFS groups. The NSFS groups are largely similar in terms of parental, household and child characteristics, although a few significant differences exist; the average age of the respondent (41.66 v. 40.52 years, $P<0.01$ ) and the proportion of fathers $(57 \cdot 4 \% \quad v .47 \cdot 4 \%, P<0 \cdot 01)$ and high-income households ( $49 \cdot 0 \% v .39 \cdot 6 \%, P<0 \cdot 01)$ responding to the survey are higher in the NOFRUIT group than in the other two NSFS groups, and the proportion of combined schools - and consequently the FREEFRUIT group - is higher in the sparsely populated North region than in other regions of Norway $(38 \cdot 9 \% v \cdot 17 \cdot 0 \%, P<0 \cdot 01)$. We control for these differences between the three NSFS groups in the multivariate regression models described below.

The sample seems representative in terms of parental age, gender and geographic region, while the percentage of the sample that has attended some form of university or college is somewhat lower than corresponding data from Statistics Norway $(34 \cdot 1 \% v .39 \cdot 6 \%)$.

\section{Associations between participation in the Norwegian} School Fruit Scheme and fruit and vegetable intake

Results of the multivariate regression models for child/ parental fruit intake (FRC/FRP), vegetable intake (VEC/VEP) and total F\&V intake (FRVEC/FRVEP) are reported in Table 2. The results of the FRC model suggest that, controlling for possibly confounding factors, children who receive free school fruit (FREEFRUIT) are on average predicted to eat $1 \cdot 80$ fruit portions/d. These predictions are calculated based on the regression coefficients of the FRC model in Table 2 with FREEFRUIT equal to one and using sample means for the other explanatory variables in the model. On the other hand, children who attend a primary school with no school fruit arrangement (NOFRUIT) are predicted to eat 1.44 fruit portions/d. Thus, on average, FREEFRUIT children eat 0.36 more fruit portions daily - or $25.0 \%$ more fruits - than NOFRUIT children $(P<0 \cdot 001)$.

Children who attend fruit subscription schools (SUBFRUIT) are on average predicted to eat 1.68 fruit portions/d, i.e. $0 \cdot 24$ more fruit portions daily - or $16 \cdot 7 \%$ more fruits than NOFRUIT children $(P<0.001)$. When we instead estimate the FRC model with the SUBFRUIT group split into subscribing and non-subscribing children, the coefficient on SUBFRYES is $0.43(P<0.001)$, while the coefficient on SUBFRNO is $0 \cdot 13(P=0 \cdot 063)$. The NSFS coefficients from this alternative model specification for FRC and the remaining five $\mathrm{F} \& \mathrm{~V}$ variables are reported in the Appendix.

Interestingly, results of the FRP model in Table 2 suggest that parents of children who attend FREEFRUIT schools eat significantly more fruits than parents of children who attend NOFRUIT schools. At respectively 1.71 and

Table 1 Variable descriptions and means by NSFS group and for the total sample: parents of primary-school children ( $n$ 1423) who responded to an Internet survey on behalf of themselves and their children, Norway, March 2011

\begin{tabular}{|c|c|c|c|c|c|}
\hline & & $\begin{array}{l}\text { NOFRUIT } \\
(n \text { 295) }\end{array}$ & $\begin{array}{c}\text { SUBFRUIT } \\
(n \text { 854) }\end{array}$ & $\begin{array}{l}\text { FREEFRUIT } \\
\quad(n \text { 274) }\end{array}$ & $\begin{array}{r}\text { TOTAL } \\
(n 1423)\end{array}$ \\
\hline Variable & Description & Mean & Mean & Mean & Mean \\
\hline \multicolumn{6}{|c|}{ Parental/HH characteristics } \\
\hline Age & Respondent age* & $41 \cdot 66$ & $40 \cdot 51$ & $40 \cdot 56$ & $40 \cdot 76$ \\
\hline Female & Respondent is female: 1 & 0.43 & 0.53 & 0.52 & 0.51 \\
\hline Married/cohabiting & Respondent is married or cohabiting: 1 & 0.88 & 0.90 & 0.91 & 0.90 \\
\hline University & Respondent has attended university: 1 & 0.36 & 0.34 & 0.34 & 0.34 \\
\hline High income & $\mathrm{HH}$ income is NOK 800000 or higher: $1+$ & 0.49 & $0 \cdot 41$ & $0 \cdot 37$ & 0.42 \\
\hline Inc. missing & $\mathrm{HH}$ income is unknownł & 0.03 & 0.08 & 0.07 & 0.06 \\
\hline South or East & HH from southern or eastern region: 1 & 0.61 & 0.51 & $0 \cdot 36$ & 0.50 \\
\hline West & $\mathrm{HH}$ from western region: 1 & 0.27 & 0.31 & $0 \cdot 30$ & $0 \cdot 30$ \\
\hline Central & $\mathrm{HH}$ from central region: 1 & 0.06 & 0.09 & $0 \cdot 11$ & 0.09 \\
\hline North & $\mathrm{HH}$ from northern region: 1 & 0.06 & $0 \cdot 10$ & $0 \cdot 23$ & $0 \cdot 12$ \\
\hline \multicolumn{6}{|l|}{ Child characteristics } \\
\hline Girl & Child is a girl: 1 & 0.48 & 0.50 & 0.47 & 0.49 \\
\hline Grade & Child attends school grade $\S . .$. & $4 \cdot 23$ & $4 \cdot 11$ & 3.93 & $4 \cdot 10$ \\
\hline \multicolumn{6}{|l|}{ F\&V variables } \\
\hline FRC & Child fruit intake (portions/d) & $1 \cdot 43$ & 1.68 & $1 \cdot 76$ & $1 \cdot 64$ \\
\hline VEC & Child vegetable intake (portions/d) & 1.08 & $1 \cdot 15$ & $1 \cdot 10$ & $1 \cdot 13$ \\
\hline FRVEC & Child total F\&V intake (FRC + VEC) & $2 \cdot 51$ & $2 \cdot 83$ & $2 \cdot 86$ & $2 \cdot 77$ \\
\hline FRP & Parent fruit intake (portions/d) & $1 \cdot 51$ & 1.54 & $1 \cdot 66$ & $1 \cdot 56$ \\
\hline VEP & Parent vegetable intake (portions/d) & $1 \cdot 66$ & $1 \cdot 66$ & $1 \cdot 64$ & $1 \cdot 66$ \\
\hline FRVEP & Parent total F\&V intake (FRP + VEP) & $3 \cdot 18$ & $3 \cdot 20$ & $3 \cdot 31$ & $3 \cdot 22$ \\
\hline
\end{tabular}

NSFS, Norwegian School Fruit Scheme; NOFRUIT, no option for fruit subscription in school; SUBFRUIT, fruit subscription school; FREEFRUIT, free fruit school; $\mathrm{HH}$, household; F\&V, fruit and vegetable; NOK, Norwegian kroner.

*Parental age ranges from 25 to 59 years.

tThe $\mathrm{HH}$ income question had eight response alternatives, ranging from 'less than NOK 200000 per year' to 'NOK 1400000 per year or more'.

$\ddagger$ The respondents were also given the option not to respond to the $\mathrm{HH}$ income question.

$\S$ School grade ranges from 1 st to 7 th grade. 
Table 2 Regression models for child and parental F\&V intake among parents of primary-school children ( $n$ 1423) who responded to an Internet survey on behalf of themselves and their children, Norway, March 2011

\begin{tabular}{|c|c|c|c|c|c|c|c|c|c|c|c|c|}
\hline & \multicolumn{6}{|c|}{ Child F\&V intake } & \multicolumn{6}{|c|}{ Parental F\&V intake } \\
\hline & \multicolumn{2}{|c|}{ FRC } & \multicolumn{2}{|c|}{ VEC } & \multicolumn{2}{|c|}{ FRVEC } & \multicolumn{2}{|c|}{ FRP } & \multicolumn{2}{|c|}{ VEP } & \multicolumn{2}{|c|}{ FRVEP } \\
\hline & $\beta^{\star}$ & $P$ valuet & $\beta$ & $P$ value & $\beta$ & $P$ value & $\beta$ & $P$ value & $\beta$ & $P$ value & $\beta$ & $P$ value \\
\hline SUBFRUIT $\ddagger$ & 0.247 & $<0.001$ & 0.059 & 0.277 & 0.307 & $0 \cdot 001$ & 0.030 & $0 \cdot 681$ & -0.029 & $0 \cdot 611$ & 0.001 & 0.994 \\
\hline FREEFRUIT & 0.365 & $<0.001$ & 0.023 & 0.738 & 0.388 & 0.001 & $0 \cdot 193$ & 0.040 & -0.008 & 0.916 & $0 \cdot 185$ & $0 \cdot 185$ \\
\hline Age & -0.003 & 0.599 & -0.006 & $0 \cdot 161$ & -0.008 & 0.246 & 0.003 & 0.511 & -0.007 & 0.084 & -0.004 & 0.635 \\
\hline Female & 0.018 & $0 \cdot 711$ & $0 \cdot 175$ & $<0.001$ & $0 \cdot 193$ & 0.013 & $0 \cdot 164$ & 0.006 & 0.385 & $<0.001$ & 0.549 & $<0.001$ \\
\hline Married/cohabiting & -0.048 & 0.526 & -0.047 & 0.557 & -0.095 & 0.448 & 0.067 & 0.493 & -0.031 & 0.735 & 0.036 & $0 \cdot 817$ \\
\hline University & $0 \cdot 120$ & 0.018 & $0 \cdot 117$ & 0.012 & 0.237 & 0.002 & 0.091 & $0 \cdot 124$ & $0 \cdot 165$ & $<0.001$ & 0.256 & 0.003 \\
\hline High income§ & 0.099 & 0.066 & $0 \cdot 136$ & 0.006 & 0.235 & 0.005 & $0 \cdot 157$ & 0.013 & $0 \cdot 114$ & 0.017 & $0 \cdot 271$ & 0.003 \\
\hline West & -0.043 & 0.441 & -0.071 & $0 \cdot 159$ & -0.115 & 0.188 & -0.023 & 0.743 & -0.045 & 0.404 & -0.067 & 0.513 \\
\hline Central & 0.002 & 0.979 & -0.036 & 0.679 & -0.034 & 0.816 & -0.082 & 0.420 & $-0 \cdot 111$ & $0 \cdot 148$ & $-0 \cdot 192$ & $0 \cdot 195$ \\
\hline North & $-0 \cdot 192$ & 0.011 & -0.067 & 0.400 & -0.260 & 0.040 & -0.259 & 0.003 & $-0 \cdot 247$ & $<0.001$ & -0.506 & $<0.001$ \\
\hline Girl & $0 \cdot 152$ & 0.001 & $0 \cdot 117$ & 0.007 & 0.270 & $<0.001$ & $1 \cdot 154$ & $<0.001$ & $1 \cdot 732$ & $<0.001$ & $2 \cdot 886$ & $<0.001$ \\
\hline Grade & -0.006 & 0.666 & 0.002 & 0.856 & -0.003 & $0 \cdot 863$ & 0.030 & 0.681 & -0.029 & 0.611 & 0.001 & 0.994 \\
\hline Constant & $1 \cdot 443$ & $<0.001$ & $1 \cdot 138$ & $<0.001$ & $2 \cdot 581$ & $<0.001$ & $0 \cdot 193$ & 0.040 & -0.008 & 0.916 & $0 \cdot 185$ & 0.185 \\
\hline$R^{2}$ & \multicolumn{2}{|c|}{0.043} & \multicolumn{2}{|c|}{0.041} & \multicolumn{2}{|c|}{0.051} & \multicolumn{2}{|c|}{0.026} & \multicolumn{2}{|c|}{0.087} & \multicolumn{2}{|c|}{0.062} \\
\hline No. of observations & \multicolumn{2}{|c|}{1423} & \multicolumn{2}{|c|}{1423} & \multicolumn{2}{|c|}{1423} & \multicolumn{2}{|c|}{1423} & \multicolumn{2}{|c|}{1423} & \multicolumn{2}{|c|}{1423} \\
\hline
\end{tabular}

F\&V, fruit and vegetable; FRC/FRP, child/parental fruit intake; VEC/VEP, child/parental vegetable intake; FRVEC/FRVEP, child/parental fruit and vegetable intake; SUBFRUIT, fruit subscription school; FREEFRUIT, free fruit school.

${ }^{*}$ Model coefficients $(\beta)$ estimated using ordinary least squares with sample weights.

$+P$ values are based on robust standard errors.

¥Reference groups are NOFRUIT and the South or East region. See Table 1 for variable descriptions.

§All models also control for missing income ('Inc. missing').

1.52 fruit portions/d, parents of FREEFRUIT children eat on average $0 \cdot 19$ more fruit portions daily - or $12 \cdot 5 \%$ more fruits - than parents of NOFRUIT children $(P=0 \cdot 040)$. Thus, there appear to be spillover effects running from free school fruit to higher parental fruit intake. The effect of having a fruit subscription scheme in school on parental fruit intake seems less clear, as the SUBFRUIT coefficient in the FRP model in Table 2 is small and statistically insignificant. This last result is not sensitive to how the SUBFRUIT respondents have been grouped; in the alternative FRP model specification in the Appendix, both the SUBFRYES and SUBFRNO coefficients are small and statistically insignificant.

Results of the VEC and VEP models in Table 2 suggest that there are no associations between the NSFS and child and parental vegetable intakes, as the coefficients on FREEFRUIT and SUBFRUIT in these models are small and statistically insignificant. Thus, as also reflected in the FRVEC and FRVEP models, the effect of FREEFRUIT on total F\&V intake seems to be entirely driven by changes in fruit intake.

\section{Discussion}

To the best of our knowledge, the present study is the first to assess impacts of a nationwide school fruit scheme using nationally representative data, as all nineteen counties of Norway and more than 750 different schools are represented in our sample of 1423 primary-school children and their parents. Daily provision of one piece of fruit or vegetable to primary-school children through the NSFS, either free or at a subsidized price, is found to significantly affect the children's fruit intake. On average, free school fruit and subsidized school fruit increase a child's fruit intake by 0.36 and 0.25 portions/d, respectively. These effects fall within the range of those reported in previous school fruit intervention studies; in a review of thirty studies, of which ten involved actual provision of fruits and/or vegetables in school, de Sa and Lock ${ }^{(3)}$ found that among the twenty-three studies that reported significant effects at follow-up, the intervention effect ranged from $0 \cdot 14$ to 0.99 portions/d.

The estimated effects of the NSFS in the present study are measured while the children attend primary school, and not in a later follow-up survey. Thus, we do not know whether all or at least some of the effects of free or subsidized school fruit are sustained in the medium term (1-3 years) and subsequently into adulthood. The evidence on the medium-term effects of other school fruit interventions is both scarce and mixed, ranging from no effects in England ${ }^{(10,11)}$, to small but significant effects in the Netherlands ${ }^{(9)}$, and significant and relatively large effects in Norway ${ }^{(8)}$.

The data in Bere et $a l^{(8)}$ were drawn from a pilot version of the NSFS. The pilot included 6 th and 7 th grade children from thirty-eight schools in two Norwegian counties. The intervention group received free school fruit during the school year 2001/02, and follow-up surveys on F\&V intake were conducted in May 2002 and May 2005. A new survey of 6th and 7 th grade children in twenty-seven out of these thirty-eight schools was conducted in September 2008, which is about one year after the current version of the NSFS was made nationwide. Significant effects of the NSFS based on this survey 
have been reported in Bere et $_{\text {al }}{ }^{(12)}$, who found that free school fruit and subsidized school fruit increase a child's fruit intake by 0.58 and 0.23 portions/d, respectively. The present study adds to these results by presenting similar evidence from data that are nationally representative and that also include children from all seven grades of primary school.

Norwegian children who attend combined schools (grades 1-10) now receive free school fruit continuously for 10 years. This is a considerably longer time period than in previously studied school fruit interventions ${ }^{(3)}$. It seems reasonable to expect that the longer the intervention period, the more likely it is that the children's general dietary habits, or at least their F\&V intakes, will be permanently affected. Provided the current version of the NSFS will run for at least 2-3 more years, it will in 5-10 years be interesting to compare the dietary habits and in particular the F\&V intakes of young adults (ages 18-23 years) who throughout their whole primary school period were randomly assigned to one of the three main NSFS groups SUBFRUIT, FREEFRUIT or NOFRUIT. This will allow for assessing the long-term impact into adulthood of a nationwide school fruit scheme with a long intervention period. Although arguably important, such long-term impact assessments of school fruit schemes have not yet been conducted because of data availability.

Nationwide school fruit schemes have thus far been subject to only one cost-benefit analysis ${ }^{(23)}$. This is surprising considering the costs involved. For example, the total cost over 10 years for the free version of the NSFS is approximately NOK 6300 per child $(\mathrm{NOK} 3.50 / \mathrm{d} \times 180$ school days/year $\times 10$ years). Sælensminde ${ }^{(23)}$ concludes that the NSFS may be cost-effective if children on average increase their permanent $F \& V$ intake by $2.5 \mathrm{~g} / \mathrm{d}$ as a result of receiving free school fruit for 10 years. While this target appears to be well within reach, Sælensminde ${ }^{(23)}$ stresses that his evaluation includes many uncertain elements, including the general assumptions being made, which costs and benefits to include, and how to calculate these costs and benefits. Thus, there is a need for more studies that evaluate the costs of nationwide school fruit schemes against alternative uses.

Among other factors, such cost-benefit analysis should consider two factors that have been specifically addressed in the present study. First, as suggested by the above results, free school fruit may be associated with positive spillover effects in terms of affecting not only child fruit intake, but also parental fruit intake. On average, parents of children who attend a free fruit school eat 0.19 more fruit portions daily - or $12.5 \%$ more fruits than parents of children who attend a school with no school fruit arrangement. To the extent that also other studies find similar spillover effects, this will have important implications for the expected effects of school fruit schemes on population health and related healthcare costs.
Second, as reported here and in other studies, while school fruit schemes are typically found to have significant effects on fruit intake, they do not seem to affect vegetable intake ${ }^{(9,10,12)}$. This is worrying because at least in Norway, insufficient vegetable consumption represents a greater challenge than insufficient fruit consumption ${ }^{(7)}$. The long-term health benefits associated with free school fruit schemes may be smaller than anticipated if they have no effect on vegetable intake.

In light of this result, nationwide school fruit schemes such as the NSFS may need to focus more explicitly on measures that can help increase vegetable consumption. For example, while many different types of fruits are handed out through the NSFS, vegetables are mainly limited to carrots, and these are typically handed out only once per week or even less frequently. One strategy may therefore be to increase the proportion of vegetables that are handed out through the NSFS, along with attempts at making vegetables more attractive as a snack food, for example through new preparations and offering more varieties. This could in turn be supported by information to the children and their parents about the particular importance of eating more vegetables.

The results of the present study must be considered in light of its limitations. First, as noted, we estimate effects of the NSFS while the children attend primary school, and not in a later follow-up survey. Second, while nationwide natural experiments such as the NSFS are attractive, they lack some of the methodological properties of randomized controlled trials, including control over the selection of intervention and control groups. Except for some regional differences that were controlled for in the above statistical analyses, the schoolchildren in the present study are believed to be randomly assigned to the three main NSFS groups SUBFRUIT, FREEFRUIT and NOFRUIT. However, we do not have access to baseline data in absence of the NSFS, and thus we cannot conclude that households from the different NSFS groups are similar on possibly relevant observable and unobservable characteristics beyond those that were controlled for in the above statistical analyses.

Third, while our sample seems representative in terms of parental age, gender and geographic region, the percentage of the sample that has attended some form of university or college is somewhat lower than corresponding data from Statistics Norway $(34 \cdot 1 \% v .39 \cdot 6 \%)$. However, while the data from Statistics Norway include all Norwegians between 25 and 60 years of age, our study only includes parents of primary-school children in the same age range. This could explain the difference; for example, respondents between 25 and 29 years of age who already have children attending primary school might be less likely to have attended college or university than other people in the same age range. Nevertheless, overall we believe that our study uses a nationally representative sample of primaryschool children and their parents, and that it is the first 
to do so focusing on effects of a nationwide school fruit scheme.

Finally, biases may also arise from the relatively crude $\mathrm{F} \& \mathrm{~V}$ measures that were used in the survey and from the fact that child F\&V intakes were reported only by the parents and not by the children themselves. The 6th and 7 th grade children in Bere et al. ${ }^{(12)}$ reported an average $\mathrm{F} \& \mathrm{~V}$ intake of 3.05 portions/d, while in the present study the parent-reported $\mathrm{F} \& \mathrm{~V}$ intake of 6 th and 7 th grade children is $2 \cdot 71$ portions/d. In Tak et al. ${ }^{(9)}$, who evaluated effects of the Dutch Schoolgruiten Project, both the children and the parents reported the child's F\&V intake and also they found that child-reported intakes were somewhat higher than parent-reported intakes. However, the regression coefficients on the effects of the school fruit intervention were approximately the same when estimating the models with child- and parent-reported data. Analogously, although the parent-reported F\&V intakes in the present study might be somewhat low, this under-reporting is not expected to differ systematically across different groups of parents and therefore the estimated effects of NSFS participation on F\&V intakes should be correct. Finally, our study includes children from all grades of primary school, i.e. children between 6 and 13 years of age. For children less than 9 years of age, self-reporting of food intake is difficult ${ }^{(24)}$ and therefore parent-reported or parent-assisted food intake reports are preferable.

\section{Acknowledgements}

Sources of funding: This research was supported by the Research Council of Norway (grant number 199545). The Research Council of Norway had no role in the design, analysis or writing of this article. Conflict of interest declaration: The authors declare that they have no competing interests. Authors' contributions: A. $\varnothing$. drafted the manuscript and conducted the analysis. E.B. critically revised the manuscript. Both authors read and approved the final manuscript. Acknowledgements: The authors would like to thank the Norwegian Fruit and Vegetable Marketing Board for providing the data for this study, and Tore Angelsen and two anonymous reviewers for their helpful comments and suggestions.

\section{References}

1. Lien N, Lytle LA \& Klepp KI (2001) Stability in consumption of fruit, vegetables, and sugary foods in a cohort from age 14 to age 21. Prev Med 33, 217-226.

2. Mikkilä V, Räsänen L, Raitarkari OT et al. (2004) Longitudinal changes in diet from childhood into adulthood with respect to risk of cardiovascular diseases; the Cardiovascular Risk in Young Finns Study. Eur J Clin Nutr 58, 1038-1045.

3. de Sa J \& Lock K (2008) Will European agricultural policy for school fruit and vegetables improve public health?
A review of school fruit and vegetable programmes. Eur J Public Health 18, 558-568.

4. Jaime PC \& Lock K (2009) Do school based food and nutrition policies improve diet and reduce obesity? Prev Med 48, 45-53.

5. World Health Organization (2003) Diet, Nutrition and the Prevention of Chronic Diseases. Joint WHO/FAO Expert Consultation. WHO Technical Report Series no. 916. Geneva: WHO.

6. World Health Organization (2008) WHO European Action Plan for Food and Nutrition Policy 2007-2012. Copenhagen: WHO Regional Office for Europe.

7. Norwegian Fruit and Vegetable Marketing Board (2011) Totaloversikten 2000-2010. Oslo: Norwegian Fruit and Vegetable Marketing Board.

8. Bere E, Veierød MB, Skare $\varnothing$ et al. (2007) Free school fruit - sustained effect three years later. Int J Behav Nutr Phys Act $\mathbf{4}, 5$.

9. Tak NI, Te Velde SJ \& Brug J (2008) Long-term effects of the Dutch Schoolgruiten Project - promoting fruit and vegetable consumption among primary-school children. Public Health Nutr 12, 1213-1223.

10. Ransley JK, Greenwood DC, Cade JE et al. (2007) Does the school fruit and vegetable scheme improve children's diet? A non-randomised controlled trial. J Epidemiol Community Health 61, 699-703.

11. Fogarty AW, Antoniak M, Venn AJ et al. (2007) Does participation in a population-based dietary intervention scheme have a lasting impact on fruit intake in young children? Int J Epidemiol 36, 1080-1085.

12. Bere E, Hilsen M \& Klepp KI (2010) Effect of the nationwide free school fruit scheme in Norway. Br J Nutr 104, 589-594.

13. Eriksen K, Haraldsdottir J, Pederson R et al. (2003) Effect of a fruit and vegetable subscription in Danish schools. Public Health Nutr 6, 57-63.

14. Krølner R, Jørgensen TS, Aarestrup AK et al. (2012) The Boost study: design of a school- and community-based randomised trial to promote fruit and vegetable consumption among teenagers. BMC Public Health 12, 191.

15. Nathan N, Wolfenden L, Bell AC et al. (2012) Effectiveness of a multi-strategy intervention in increasing the implementation of vegetable and fruit breaks by Australian primary schools: a non-randomized controlled trial. $B M C$ Public Health 12, 651.

16. Bere E, Veierød M \& Klepp KI (2005) The Norwegian School Fruit Programme: evaluating paid vs. no-cost subscriptions. Prev Med 41, 463-470.

17. US Department of Agriculture (2011) Evaluation of the Fresh Fruit and Vegetable Program (FFVP): Interim Evaluation Report. Alexandria, VA: USDA Food and Nutrition Service.

18. European Council (2008) Council Regulation (EC) No 13/ 2009 of 18 December 2008 Amending Regulations (EC) No 1290/2005 on the Financing of the Common Agricultural Policy and (EC) No 1234/2007 Establishing a Common Organisation of Agricultural Markets and on Specific Provisions for Certain Agricultural Products (Single CMO Regulation) in Order to Set up a School Fruit Scheme. Brussels: European Council.

19. European Court of Auditors (2011) Are the School Milk and School Fruit Schemes Effective? Special Report No 10/2011. Luxembourg: European Court of Auditors.

20. Norwegian Fruit and Vegetable Marketing Board (2013) Information about the NSFS in English. http://www.skole frukt.no/om-skolefruktordningen/In-english (accessed January 2013).

21. Norwegian Ministry of Education and Research (2008) Om lov om endringar $i$ opplaeringslova og privatskolelova. Proposition No. 40 (2007-2008) to the Storting. Oslo: Norwegian Ministry of Education and Research. 
22. Imbens GW \& Wooldridge JM (2009) Recent developments in the econometrics of program evaluation. J Econ Lit $\mathbf{4 7}$, $5-86$.

23. Sælensminde K (2005) Frukt og grønnsaker i skolen. Beregning av samfunnsøkonomisk lønnsombet (Fruit and vegetables in schools. A cost-benefit analysis). Oslo: Norwegian Directorate of Health.

24. McPherson S, Hoelscher D, Alexander M et al. (2000) Dietary assessment methods among school aged children: validity and reliability. Prev Med 31, Suppl., S11-S33.

\section{Appendix}

Regression models for child and parental FEV intake with SUBFRUIT split into SUBFRYES and SUBFRNO among parents of primary-school children (n 1423) who responded to an Internet survey on behalf of themselves and their children, Norway, March 2011

\begin{tabular}{|c|c|c|c|c|c|c|c|c|c|c|c|c|}
\hline & \multicolumn{6}{|c|}{ Child F\&V intake* } & \multicolumn{6}{|c|}{ Parental F\&V intake* } \\
\hline & \multicolumn{2}{|c|}{ FRC } & \multicolumn{2}{|c|}{ VEC } & \multicolumn{2}{|c|}{ FRVEC } & \multicolumn{2}{|c|}{ FRP } & \multicolumn{2}{|c|}{ VEP } & \multicolumn{2}{|c|}{ FRVEP } \\
\hline & $\beta$ & $P$ value & $\beta$ & $P$ value & $\beta$ & $P$ value & $\beta$ & $P$ value & $\beta$ & $P$ value & $\beta$ & $P$ value \\
\hline SUBFRYES & 0.431 & $<0.001$ & 0.064 & 0.324 & 0.495 & $<0.001$ & -0.013 & 0.882 & -0.044 & 0.513 & -0.057 & 0.653 \\
\hline SUBFRNO & $0 \cdot 126$ & 0.063 & 0.056 & 0.345 & 0.182 & 0.082 & 0.058 & 0.463 & -0.019 & 0.759 & 0.039 & 0.743 \\
\hline FREEFRUIT & 0.369 & $<0.001$ & 0.023 & 0.737 & 0.392 & 0.001 & $0 \cdot 192$ & 0.041 & -0.008 & 0.913 & 0.184 & $0 \cdot 187$ \\
\hline$R^{2}$ & \multicolumn{2}{|c|}{0.043} & \multicolumn{2}{|c|}{0.041} & \multicolumn{2}{|c|}{0.051} & \multicolumn{2}{|c|}{0.026} & \multicolumn{2}{|c|}{0.087} & \multicolumn{2}{|c|}{0.062} \\
\hline No. of observations & \multicolumn{2}{|c|}{1423} & \multicolumn{2}{|c|}{1423} & \multicolumn{2}{|c|}{1423} & \multicolumn{2}{|c|}{1423} & \multicolumn{2}{|c|}{1423} & \multicolumn{2}{|c|}{1423} \\
\hline
\end{tabular}

F\&V, fruit and vegetable; FRC/FRP, child/parental fruit intake; VEC/VEP, child/parental vegetable intake; FRVEC/FRVEP, child/parental fruit and vegetable intake; SUBFRYES, child subscribes to subsidized school fruit; SUBFRNO, child does not subscribe to subsidized school fruit; FREEFRUIT, free fruit school. *These models are the same as in Table 2 except that the SUBFRUIT group has been split into subscribing (SUBFRYES) and non-subscribing (SUBFRNO) children. The coefficients on parental, household and child characteristics are omitted due to the interest of space. See Table 2 for an overview of these additional covariates and further information on how the models have been estimated. 